\title{
Genetic Markers of Brown Adipose Tissue Identity and In Vitro Brown Adipose Tissue Activity in Humans
}

Citation for published version (APA):

Nascimento, E. B. M., Sparks, L. M., Divoux, A., van Gisbergen, M. W., Broeders, E. P. M., Jorgensen, J. A., Schaart, G., Bouvy, N. D., van Marken Lichtenbelt, W. D., \& Schrauwen, P. (2018). Genetic Markers of Brown Adipose Tissue Identity and In Vitro Brown Adipose Tissue Activity in Humans. Obesity, 26(1), 135140. https://doi.org/10.1002/oby.22062

Document status and date:

Published: 01/01/2018

DOI:

10.1002/oby.22062

Document Version:

Publisher's PDF, also known as Version of record

Document license:

Taverne

Please check the document version of this publication:

- A submitted manuscript is the version of the article upon submission and before peer-review. There can be important differences between the submitted version and the official published version of record.

People interested in the research are advised to contact the author for the final version of the publication, or visit the DOI to the publisher's website.

- The final author version and the galley proof are versions of the publication after peer review.

- The final published version features the final layout of the paper including the volume, issue and page numbers.

Link to publication

\footnotetext{
General rights rights.

- You may freely distribute the URL identifying the publication in the public portal. please follow below link for the End User Agreement:

www.umlib.nl/taverne-license

Take down policy

If you believe that this document breaches copyright please contact us at:

repository@maastrichtuniversity.nl

providing details and we will investigate your claim.
}

Copyright and moral rights for the publications made accessible in the public portal are retained by the authors and/or other copyright owners and it is a condition of accessing publications that users recognise and abide by the legal requirements associated with these

- Users may download and print one copy of any publication from the public portal for the purpose of private study or research.

- You may not further distribute the material or use it for any profit-making activity or commercial gain

If the publication is distributed under the terms of Article $25 \mathrm{fa}$ of the Dutch Copyright Act, indicated by the "Taverne" license above, 


\title{
Genetic Markers of Brown Adipose Tissue Identity and In Vitro Brown Adipose Tissue Activity in Humans
}

\author{
Emmani B.M. Nascimento (1D ${ }^{1}$, Lauren M. Sparks ${ }^{2}$, Adeline Divoux ${ }^{2}$, Marike W. van Gisbergen ${ }^{3}$, Evie P.M. Broeders ${ }^{1,4}$, \\ Johanna A. Jörgensen ${ }^{1}$, Gert Schaart ${ }^{l}$, Nicole D. Bouvy ${ }^{4}$, Wouter D. van Marken Lichtenbelt ${ }^{1}$, and Patrick Schrauwen ${ }^{l}$
}

Objective: Human brown adipose tissue (BAT) activity decreases with age and obesity. In addition to uncoupling protein 1 (UCP1), several genetic markers of BAT in humans have been published. However, the link between human BAT activity and genetic markers has been inadequately explored.

Methods: White adipose tissue (WAT) and BAT biopsies were obtained from 16 patients undergoing deep neck surgery. In vitro differentiated adipocytes were used to measure norepinephrine-stimulated mitochondrial uncoupling as a measure of in vitro BAT activity. Gene expression was determined in adipose tissue biopsies.

Results: Norepinephrine increased in vitro BAT activity in adipocytes derived from human BAT, and this increase was abolished by propranolol. Furthermore, in vitro BAT activity showed a negative correlation to age and BMI. UCP1 messenger RNA (mRNA) expression showed a positive correlation to in vitro BAT activity, while zinc finger protein of cerebellum 1 (ZIC1) mRNA showed a negative correlation to in vitro BAT activity. In human BAT biopsies, UCP1 mRNA showed negative correlations to age and BMI, while ZIC1 mRNA showed positive correlations to age and BMI.

Conclusions: Differentiated adipocytes derived from human BAT maintain intrinsic characteristics of the donor. High ZIC1 mRNA does not necessarily reflect high BAT activity.

Obesity (2018) 26, 135-140. doi:10.1002/oby.22062

\section{Introduction}

An imbalance of increased caloric intake over energy expenditure leads to the storage of excess energy in white adipose tissue (WAT), ultimately resulting in obesity. Currently, obesity is a worldwide health issue that predisposes people to develop other metabolic disorders, including type 2 diabetes mellitus, cardiovascular disease, and cancer (1). Brown adipose tissue (BAT) fulfills the opposite function of WAT by preventing hypothermia in hibernating mammals and young infants. The unique characteristic of BAT is its ability to uncouple electron transport from ATP production via uncoupling protein 1 (UCP1) in the electron transport chain, resulting in heat production while using glucose and fatty acids as substrates (2). Therefore, activating BAT might be a strategy to combat obesity and obesity-related metabolic disorders.

The interest in human BAT was renewed with the discovery of active BAT following cold exposure in adult humans (3-5). We have previously shown that in vivo human BAT activity correlates negatively with body mass index (BMI) (3), suggesting that the reactivation of BAT in people with obesity might be a strategy to promote weight loss $(6,7)$. Furthermore, it has been suggested that human BAT activity decreases with age $(8,9)$. However, in these studies, BAT activity was determined indirectly by measuring cold-induced glucose uptake in the neck/supraclavicular region by using 2-deoxy-2- $\left({ }^{18} \mathrm{~F}\right) \mathrm{flu}$ oroglucose and positron emission tomography (PET)/computed tomography analysis. To date, it is unknown whether intrinsic mitochondrial uncoupling capacity of brown adipocytes is altered with obesity or aging. Therefore, the first aim of the present study was to examine the capacity for mitochondrial uncoupling in differentiated adipocytes derived from human BAT from volunteers with a wide range in age and BMI and to test the hypothesis that aging and obesity reduce intrinsic mitochondrial uncoupling activity in human BAT.

Studies in humans that include human BAT biopsies have mainly focused on gene expression to identify BAT. However, the field of

\footnotetext{
${ }^{1}$ Department of Human Biology and Human Movement Sciences, NUTRIM School for Nutrition and Translational Research in Metabolism, Maastricht University Medical Center, Maastricht, The Netherlands. Correspondence: Emmani B.M. Nascimento (e.nascimento@maastrichtuniversity.nl) ${ }^{2}$ Translational Research Institute for Metabolism and Diabetes, Florida Hospital, Orlando, Florida, USA ${ }^{3}$ Department of Radiotherapy, GROW - School for Oncology and Developmental Biology, Maastricht Comprehensive Cancer Center, Maastricht University Medical Center, The Netherlands ${ }^{4}$ Department of General Surgery, NUTRIM School for Nutrition and Translational Research in Metabolism, Maastricht University Medical Center, Maastricht, The Netherlands.
}

Funding agencies: This work was supported by the Dutch Diabetes Research Foundation (2014.11.1714), the Netherlands Organization for Scientific Research (TOP 91209037), and EU FP7 project DIABAT (HEALTH-F2-2011-278373).

Disclosure: The authors declared no conflict of interest.

Clinical trial registration: metc.mumc.nl identifier METC 10-3-012; ClinicalTrials.gov identifier NCT03111719.

Received: 10 August 2017; Accepted: 4 October 2017; Published online 27 November 2017. doi:10.1002/oby.22062 
BAT has been further complicated by the discovery of beige, brite, or recruitable brown adipocytes $(10,11)$. Just like brown adipocytes, these adipocytes express high levels of UCP1 in the mitochondria, enabling uncoupling. Different genetic markers have been found to demonstrate the presence of UCP1-expressing adipocytes in mouse and man. These markers have provided evidence that human BAT can be composed out of pure brown or beige adipocytes or can be a mixture of beige and brown adipocytes (12-15). However, to date, it remains unknown whether genetic markers of UCP1-expressing adipocytes have predictive value regarding BAT activity. Therefore, the second aim of the current study was to examine whether previously described genetic markers have predictive value for mitochondrial uncoupling capacity in differentiated adipocytes derived from human BAT.

\section{Methods}

\section{Study approval}

The study was reviewed and approved by the ethics committee of Maastricht University Medical Center (METC 10-3-012, NL31367.068.10). Informed consent was obtained before surgery, and participants did not receive a stipend.

\section{Human biopsies and primary adipocyte cultures}

Paired human BAT and subcutaneous WAT biopsies were collected during deep neck surgery in patients with normal thyroid function. Stromal vascular fractions were obtained from adipose tissue biopsies by using collagenase digestion. Isolated cells were grown to confluence before differentiation was initiated as previously described (16).

\section{Mitochondrial respiration experiments}

The stromal vascular fractions derived from adipose tissue biopsies were plated in XF96 cell culture microplates (Agilent Technologies, Santa Clara, California). After cells were fully differentiated, oxygen consumption and mitochondrial function were measured by using the Seahorse XF96 extracellular flux analyzer from Agilent Technologies. Cells were incubated for 1 hour at $37^{\circ} \mathrm{C}$ in unbuffered $\mathrm{XF}$ assay medium supplemented with GlutaMAX $(2 \mathrm{mM})$ (Thermo Fisher Scientific, Waltham, Massachusetts), sodium pyruvate $(1 \mathrm{mM})$, and glucose $(25 \mathrm{mM})$. The basal oxygen consumption rate was measured, followed by an injection of $1 \mu \mathrm{M}$ oligomycin and then an injection of $1 \mu \mathrm{M}$ norepinephrine (NE). Oligomycin, propranolol, and NE were purchased from Sigma-Aldrich (St. Louis, Missouri). Mitochondrial uncoupling was examined as mitochondrial respiration after the inhibition of ATP synthase with oligomycin (which was set to 100\%), thus reflecting mitochondrial uncoupling because of proton leak. Data were plotted as a percentage calculated from the fourth measurement after the injection with oligomycin.

\section{RNA isolation and quantitative polymerase chain reaction analysis}

RNA was isolated from human adipose tissue biopsied material and cultured adipocytes by using TRIzol extraction (Thermo Fisher Scientific) followed by purification by using the RNeasy kit from Qiagen (Hilden, Germany) according to the manufacturer's instructions. Complementary DNA was synthesized by using the High-Capacity RNA-to-cDNA Kit from Applied Biosystems (Foster City, California) according to the manufacture's instructions. Quantitative polymerase chain reactions were

\begin{tabular}{lccc}
\hline \multicolumn{4}{l}{ TABLE $\mathbf{1}$ Human subject characteristics } \\
\hline Subject & Sex & Age $(\mathbf{y})$ & BMI $\left(\mathbf{k g} / \mathbf{m}^{2}\right)$ \\
\hline $\mathbf{1}$ & $\mathrm{F}$ & 45 & 22.6 \\
$\mathbf{2}$ & $\mathrm{F}$ & 48 & 21.9 \\
$\mathbf{3}$ & $\mathrm{F}$ & 66 & 33.6 \\
$\mathbf{4}$ & $\mathrm{F}$ & 58 & 29.4 \\
$\mathbf{5}$ & $\mathrm{F}$ & 69 & 30.0 \\
$\mathbf{6}$ & $\mathrm{F}$ & 76 & 28.4 \\
$\mathbf{7}$ & $\mathrm{F}$ & 68 & 31.9 \\
$\mathbf{8}$ & $\mathrm{M}$ & 51 & 26.6 \\
$\mathbf{9}$ & $\mathrm{F}$ & 59 & 26.0 \\
$\mathbf{1 0}$ & $\mathrm{F}$ & 31 & 18.6 \\
$\mathbf{1 1}$ & $\mathrm{F}$ & 55 & 22.5 \\
$\mathbf{1 2}$ & $\mathrm{F}$ & 48 & 25.1 \\
$\mathbf{1 3}$ & $\mathrm{F}$ & 29 & 26.0 \\
$\mathbf{1 4}$ & $\mathrm{F}$ & 47 & 22.3 \\
$\mathbf{1 5}$ & $\mathrm{F}$ & 19 & 16.1 \\
$\mathbf{1 6}$ & $\mathrm{M}$ & 33 & 21.2 \\
\hline
\end{tabular}

performed on a CFX384 Touch Real-Time PCR Detection System from BioRad Laboratories (Hercules, California). Gene expression was calculated by using the $2^{-\Delta \Delta \mathrm{Ct}}$ method. Relative gene expression was normalized to TATA box-binding protein. The following SYBR green primers were used to analyze gene expression: adiponectin (ADIPQ) (fwd: accag gaaaccacgactcaa, rev: accaataagacctggatctcctttc), leptin (fwd: gctgtgcccatc caaaaagtcc, rev cccaggaatgaagtccaaaccg), and zinc finger protein of cerebellum 1 (ZIC1) (fwd: acatgaaggtccacgaatcct, rev: cttgtggtcgggttgtctgt). Primers detecting mitochondrial tumor suppressor 1 (MTUS1) (Hs00368183_m1) and potassium channel subfamily $\mathrm{k}$ member 3 (KCNK3) (Hs00605529_m1) were from Applied Biosystems. Primers detecting adipocyte protein 2 (AP2) (13), UCP1 (17), epithelial v-like antigen (EVA1) (12), and TATA box-binding protein (12) have been described previously.

\section{Statistics}

For respiration experiments, differences were analyzed by using a twoway analysis of variance (ANOVA) in GraphPad Prism (GraphPad Software Inc., San Diego, California), and the correlation analyses (Spearman) were also performed in GraphPad Prism. $P<0.05$ was considered significantly different.

\section{Results}

\section{NE-stimulated mitochondrial uncoupling is specific for differentiated adipocytes derived from human BAT and is dependent on $\beta$-adrenergic receptor}

Paired BAT and WAT biopsies were collected from 16 individuals with a wide range in BMI and age undergoing deep neck surgery (Table 1) and were used for culturing preadipocytes from the stromal vascular fraction. In vitro BAT activity was measured as mitochondrial uncoupling followed by stimulation with natural $\beta$-adrenergic receptor agonist NE. In accordance with the characteristic capacity of BAT, acute stimulation with $\mathrm{NE}$ in differentiated 

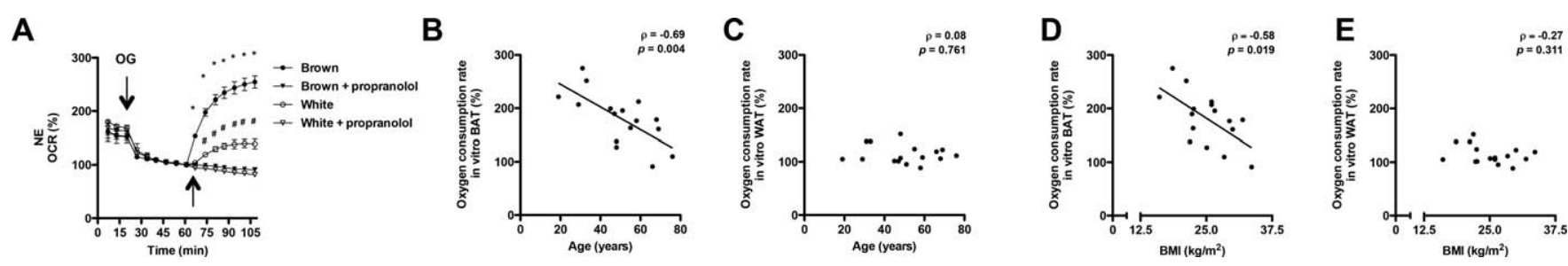

Figure 1 Mitochondrial uncoupling capacity in differentiated adipocytes derived from human BAT and the relationship to the donor's age and BMI. (A) Oxygen consumption rate (OCR) was measured in oligomycin (OG)-treated differentiated adipocytes derived from BAT (black circles) and WAT (white circles) following $1 \mu \mathrm{M}$ NE (upward-pointing arrow). Differentiated adipocytes derived from human BAT (black triangles) and WAT (white triangles) were pretreated for 1 hour with $1 \mu \mathrm{M}$ propranolol and, subsequently, OCR was measured in OG-treated differentiated adipocytes following $1 \mu \mathrm{M}$ NE. Results are presented as mean \pm SD measured in quadruplicate $(n=1)$. ${ }^{\star} P<0.05$ for brown versus brown + propranolol. ${ }^{\#} P<0.05$ for white versus white + propranolol. (B) Spearman correlation analysis $(n=16)$ of NEstimulated OCR in differentiated adipocytes derived from human BAT to age (years). (C) Spearman correlation analysis ( $n=16$ ) of NE-stimulated OCR in differentiated adipocytes derived from human WAT to age (years). (D) Spearman correlation analysis $(n=16)$ of NE-stimulated OCR in differentiated adipocytes derived from human BAT to BMI (kilograms/meters squared). (E) Spearman correlation analysis of NE-stimulated OCR in differentiated adipocytes derived from human WAT to BMI (kilograms/meters squared)

adipocytes derived from human BAT significantly increased mitochondrial uncoupling to $256 \pm 3.3 \%$, an effect that was largely absent in differentiated adipocytes derived from human subcutaneous WAT coming from the same region (125 $\pm 9.0 \%$; Figure $1 \mathrm{~A})$, which is in agreement with our previously published results (16). To demonstrate that this mitochondrial uncoupling is directly due to $\beta$-adrenergic stimulation, we used $\beta$-adrenergic receptor antagonist propranolol. Indeed, NE-stimulated mitochondrial uncoupling was completely abolished by propranolol in adipocytes derived from human BAT (Figure 1A).

\section{NE-stimulated mitochondrial uncoupling in differentiated adipocytes derived from human BAT is related to age and BMI}

Differentiated adipocytes derived from human BAT in the current study originated from volunteers with a wide range in BMI and age. Although age and BMI are related to each other, this allowed us to investigate whether the intrinsic NE-stimulated mitochondrial uncoupling activity of adipocytes derived from human BAT or WAT was related to the BMI or age of the donor. NE-stimulated mitochondrial
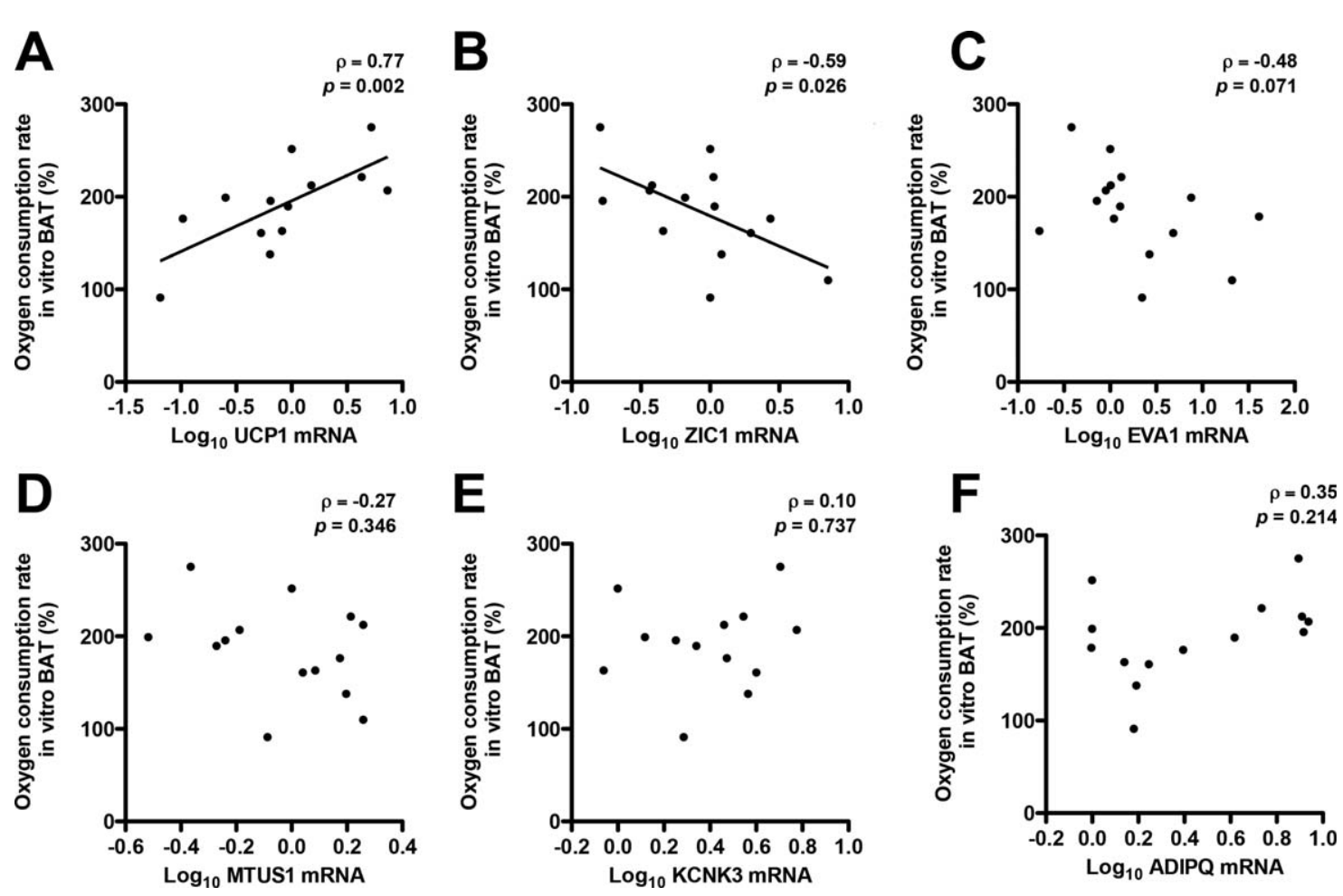

Figure 2 Correlation of genetic markers for human BAT to in vitro BAT activity. Spearman correlation analysis $(n=15)$ of $(\mathbf{A})$ UCP1, (B) ZIC1, (C) EVA1, (D) MTUS1, (E) KCNK3, and (F) ADIPQ mRNA expression to NE-stimulated oxygen consumption rate (OCR) in differentiated adipocytes derived from human BAT. 


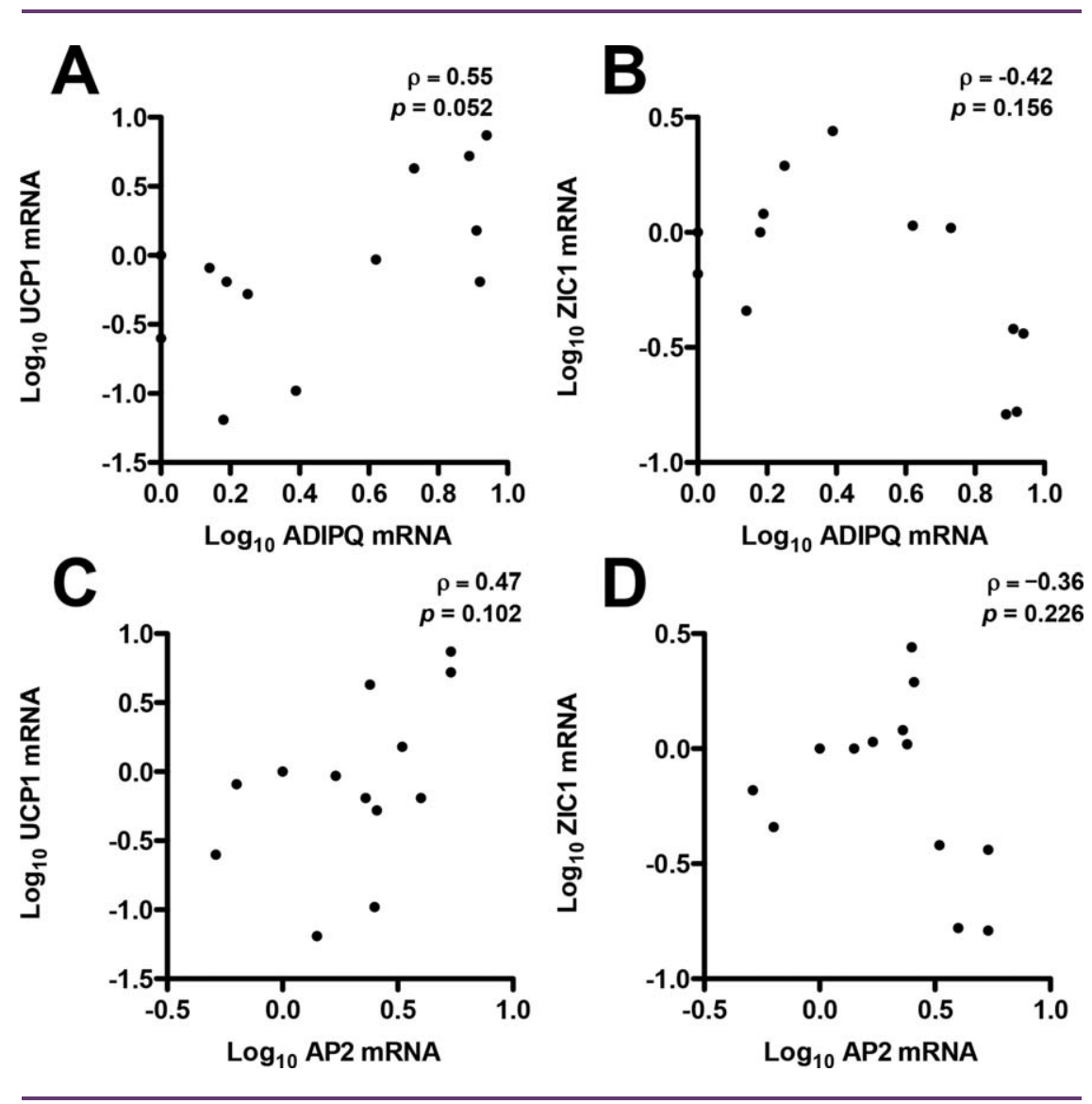

Figure 3 Correlation of genetic markers of BAT in differentiated adipocytes derived from human deep neck BAT biopsies. (A,B) Spearman correlation analysis $(n=15)$ of UCP1 and ZIC1 mRNA expression to ADIPQ mRNA expression in differentiated adipocytes derived from human BAT. (C,D) Spearman correlation analysis $(n=15)$ of UCP1 and ZIC1 mRNA expression to AP2 mRNA expression in differentiated adipocytes derived from human BAT.

uncoupling in differentiated adipocytes derived from human BAT displayed a negative correlation to age $(\rho=-0.69 ; P=0.004)$ and BMI $(\rho=-0.58 ; P=0.019)$, while no such correlation was established in differentiated adipocytes derived from human WAT (Figure $1 \mathrm{~B}-1 \mathrm{E})$. These findings are consistent with previous reports demonstrating that 2-deoxy-2- $\left({ }^{18} \mathrm{~F}\right)$ fluoroglucose glucose uptake in the human neck region is negatively associated with age and BMI $(3,5,8)$.

\section{ZIC1 messenger RNA negatively correlates with in vitro BAT activity in differentiated adipocytes derived from human BAT}

The exact nature of human BAT is currently under debate. Thus far, studies devoted to genetic markers of beige and brown adipocytes in human BAT biopsies have included ZIC1 $(13,18)$, EVA1 $(12,18)$, KCNK3 (19), and MTUS1 (19) with the aim to distinguish human brown and beige from white adipocytes. Next, we investigated how messenger RNA (mRNA) expression of these genes relates to in vitro BAT activity measured in in vitro differentiated adipocytes. UCP1 mRNA was positively associated with intrinsic mitochondrial uncoupling activity in differentiated adipocytes derived from human BAT ( $\rho=0.77 ; P=0.002$ ) (Figure 2A). Interestingly, ZIC1 mRNA showed a negative correlation to in vitro BAT activity $(\rho=-0.59$; $P=0.026$ ) (Figure 2B). mRNA expression of EVA1, MTUS1, and $\mathrm{KCNK} 3$ did not correlate with in vitro BAT activity (Figure $2 \mathrm{C}-2 \mathrm{E}$ ). In order to monitor the effects of differentiation in these experiments, we examined ADIPQ mRNA expression and correlated that to in vitro BAT activity. ADIPQ mRNA did not show a correlation with in vitro BAT activity (Figure $2 \mathrm{~F}$ ), indicating that in vitro BAT activity was not dependent on the differentiation state of the adipocytes because ADIPQ is an important indicator of adipocyte differentiation $(20,21)$.

No correlations to ADIPQ or AP2 were detected for UCP1 mRNA (Figure 3A-3C). Also, no correlations to ADIPQ or AP2 were detected for ZIC1 mRNA expression (Figure 3B-3D). These results further indicate that differentiation state does not seem to be a driver for UCP1 or ZIC1 expression in adipocytes derived from human BAT.

\section{Expression of genetic markers in human BAT biopsies from the neck}

Next, the previously discussed markers were analyzed in paired BAT and WAT biopsies of adult human subjects undergoing deep neck surgery. As expected, UCP1 expression was higher in BAT 

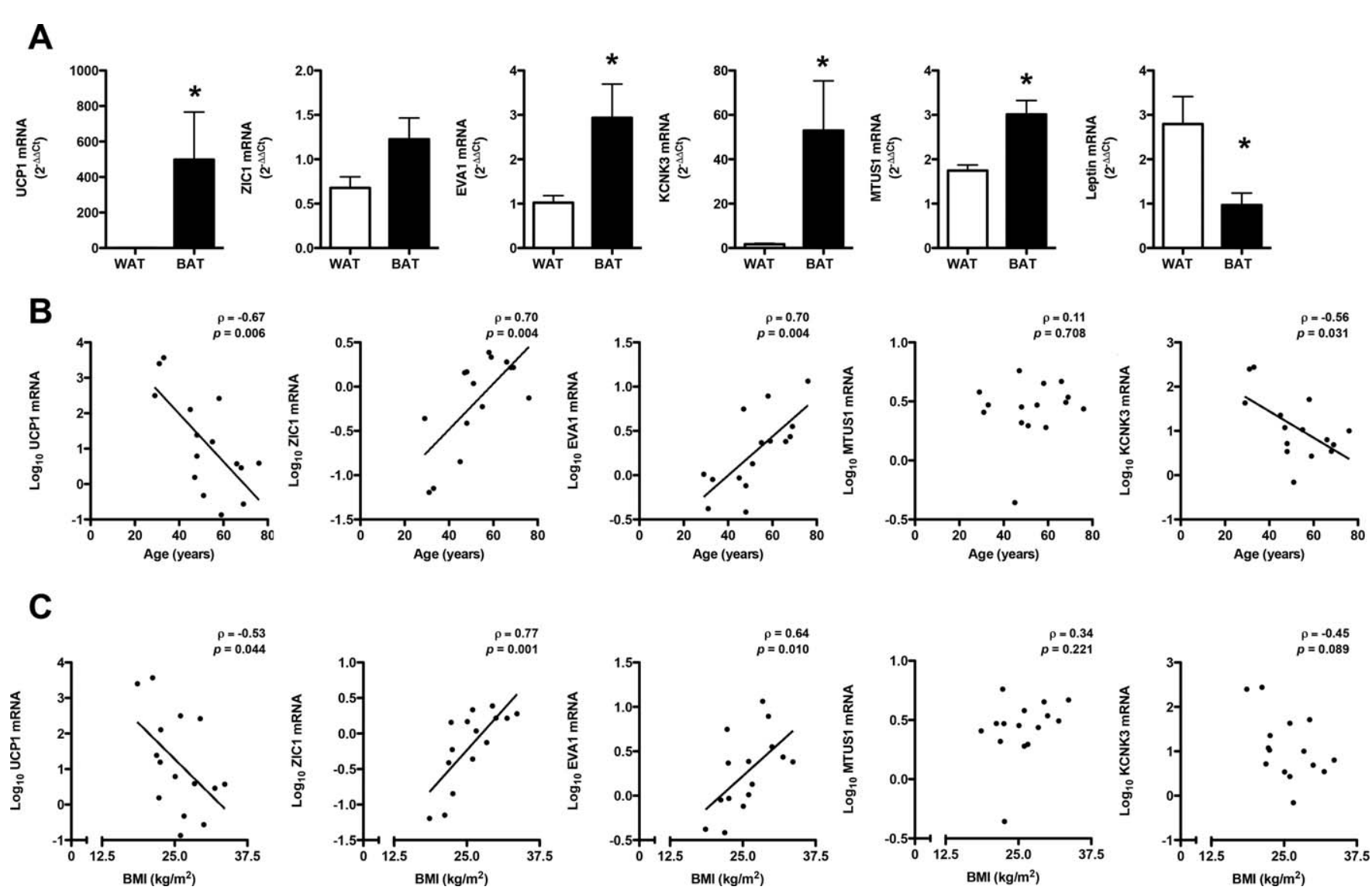

Figure 4 Genetic markers of BAT in human deep neck biopsies and the relationship to the donor's age and BMI. (A) mRNA expression of UCP1, ZIC1, EVA1, MTUS1, KCNK3, and leptin examined in human BAT biopsies (black bars) and WAT biopsies (white bars). A Student $t$ test was used to compare WAT with BAT. Results are presented as mean \pm SEM $(n=15)$. ${ }^{*} P<0.05$. (B) Spearman correlation analysis $(n=15)$ of UCP1, ZIC1, EVA1, MTUS1, and KCNK3 mRNA to age (years). (C) Spearman correlation analysis $(n=15)$ of UCP1, ZIC1, EVA1, MTUS1, and KCNK3 mRNA to BMI (kilograms/meters squared).

biopsies compared with WAT biopsies (Figure 4A), and leptin expression was higher in WAT biopsies compared with BAT biopsies (Figure 4A). In addition, expression of MTUS1, EVA1, and KCNK3 was higher in human BAT biopsies compared with WAT biopsies (Figure 4A). Although ZIC1 mRNA was increased in BAT biopsies compared with WAT biopsies, this increase did not reach statistical significance (Figure 4A).

\section{Correlation analysis of genetic markers in human BAT biopsies from the neck to age and BMI}

Because our BAT biopsies were derived from volunteers with a wide range of age and BMI, we next determined if these markers were associated with increased age and BMI. Interestingly, UCP1 and KCNK3 displayed a negative correlation to age $(\rho=-0.67$; $P=0.006$ and $\rho=-0.56 ; P=0.031)$, while only UCP1 displayed a negative correlation to BMI $(\rho=-0.53 ; P=0.044)$ (Figure 4B$4 \mathrm{C})$. In contrast, ZIC1 and EVA1 showed a positive correlation to age $(\rho=0.70 ; P=0.004$ and $\rho=0.70 ; P=0.004)$ and BMI $(\rho=0.77 ; P=0.001$ and $\rho=0.64 ; P=0.010)$ (Figure 4B-4C). No correlations to age or BMI were detected for MTUS1 (Figure 4B-4C).

\section{Discussion}

In the present study, we show that the intrinsic capacity of differentiated adipocytes derived from human BAT for mitochondrial uncoupling decreases with age and obesity. Although it cannot be deduced from the current study which factors are responsible for this reduction in BAT activity in humans, the strong correlation with UCP1 and not other markers may suggest that an age- or BMIrelated downregulation of UCP1 may be key. It has been reported that higher human in vivo BAT activity changes metabolism through increased energy expenditure $(6,16)$. However, the current topic of debate questions whether we fully grasp the complete thermogenic potential of active human BAT (22). The finding that ZIC1 was positively associated with age and BMI and negatively associated with BAT activity is interesting because, to the best of our knowledge, no links have been established between BAT activity and ZIC1. ZIC1 does show specificity for human adipose tissue biopsies taken from the deep neck region in adults compared with WAT $(13,14)$. In the current study, we have used BAT biopsies derived from the neck area. Further research would be required to establish a similar role for ZIC1 in other human BAT depots. In human neonates, ZIC1 expression is higher in interscapular adipose tissue compared with visceral adipose tissue (23); however, no connections have been made to assess the involvement of age. ZIC1 overexpression in 
pluripotent murine stem cells has a negative impact on adipogenesis and expression of mitochondrial proteins (24), which fits with our findings that high ZIC1 expression is linked to low in vitro BAT activity. ZIC1 is a transcription factor with zinc finger domains primarily found in the adult cerebellum. High levels of ZIC1 have been detected in liposarcomas (25); however, hypermethylation of $\mathrm{ZIC} 1$ has been detected in gastric cancer (26). Future studies using differentiated adipocytes derived from human BAT could be used to unravel the mechanisms underlying the age-related decline in BAT activity with a specific interest for the contribution of ZIC1.

\section{Conclusion}

We have demonstrated that in vitro BAT activity decreases with age and BMI comparable with in vivo BAT activity in humans. Furthermore, we have provided evidence that previously reported genes found to identify beige and/or brown adipocytes may not have predictive value regarding in vitro BAT activity and perhaps also in vivo BAT activity in humans. 0

\section{Acknowledgments}

The authors would like to thank all participants who joined the study.

\section{(C) 2017 The Obesity Society}

\section{References}

1. World Health Organization. Obesity: Preventing and Managing the Global Epidemic. Report of a WHO Consultation. WHO Technical Report Series 894 Geneva: WHO; 2000.

2. Cannon B, Nedergaard J. Brown adipose tissue: function and physiological significance. Physiol Rev 2004;84:277-359.

3. van Marken Lichtenbelt WD, Vanhommerig JW, Smulders NM, et al. Coldactivated brown adipose tissue in healthy men. N Engl J Med 2009;360:1500-1508.

4. Virtanen KA, Lidell ME, Orava J, et al. Functional brown adipose tissue in healthy adults. New Engl J Med 2009;360:1518-1525.

5. Saito M, Okamatsu-Ogura Y, Matsushita M, et al. High incidence of metabolically active brown adipose tissue in healthy adult humans: effects of cold exposure and adiposity. Diabetes 2009;58:1526-1531.

6. Yoneshiro T, Aita S, Matsushita M, et al. Recruited brown adipose tissue as an antiobesity agent in humans. J Clin Invest 2013;123:3404-3408.
7. Hanssen MJ, van der Lans AA, Brans B, et al. Short-term cold acclimation recruits brown adipose tissue in obese humans. Diabetes 2016;65:1179-1189.

8. Cypess AM, Lehman S, Williams G, et al. Identification and importance of brown adipose tissue in adult humans. New Engl J Med 2009;360:1509-1517.

9. Yoneshiro T, Aita S, Matsushita M, et al. Age-related decrease in cold-activated brown adipose tissue and accumulation of body fat in healthy humans. Obesity (Silver Spring) 2011;19:1755-1760.

10. Petrovic N, Walden TB, Shabalina IG, Timmons JA, Cannon B, Nedergaard J. Chronic peroxisome proliferator-activated receptor gamma (PPARgamma) activation of epididymally derived white adipocyte cultures reveals a population of thermogenically competent, UCP1-containing adipocytes molecularly distinct from classic brown adipocytes. J Biol Chem 2010;285:7153-7164.

11. Schulz TJ, Huang TL, Tran TT, et al. Identification of inducible brown adipocyte progenitors residing in skeletal muscle and white fat. Proc Natl Acad Sci USA 2011;108:143-148.

12. Wu J, Bostrom P, Sparks LM, et al. Beige adipocytes are a distinct type of thermogenic fat cell in mouse and human. Cell 2012;150:366-376.

13. Jespersen NZ, Larsen TJ, Peijs L, et al. A classical brown adipose tissue mRNA signature partly overlaps with brite in the supraclavicular region of adult humans. Cell Metab 2013;17:798-805.

14. Cypess AM, White AP, Vernochet $\mathrm{C}$, et al. Anatomical localization, gene expression profiling and functional characterization of adult human neck brown fat. Nat Med 2013;19:635-639.

15. Tews D, Schwar V, Scheithauer M, et al. Comparative gene array analysis of progenitor cells from human paired deep neck and subcutaneous adipose tissue. Mol Cell Endocrinol 2014;395:41-50.

16. Broeders EP, Nascimento EB, Havekes B, et al. The bile acid chenodeoxycholic acid increases human brown adipose tissue activity. Cell Metab 2015;22:418-426

17. Arrighi N, Moratal C, Clement N, et al. Characterization of adipocytes derived from fibro/adipogenic progenitors resident in human skeletal muscle. Cell Death Dis 2015;6:e1733-e1742.

18. Lidell ME, Betz MJ, Dahlqvist Leinhard O, et al. Evidence for two types of brown adipose tissue in humans. Nat Med 2013;19:631-634.

19. Shinoda K, Luijten IH, Hasegawa Y, et al. Genetic and functional characterization of clonally derived adult human brown adipocytes. Nat Med 2015;21:389-394.

20. Martella E, Bellotti C, Dozza B, Perrone S, Donati D, Lucarelli E. Secreted adiponectin as a marker to evaluate in vitro the adipogenic differentiation of human mesenchymal stromal cells. Cytotherapy 2014;16:1476-1485.

21. Farmer SR. Regulation of PPARgamma activity during adipogenesis. Int J Obes 2005;29(suppl 1):S13-S16.

22. Leitner BP, Huang S, Brychta RJ, et al. Mapping of human brown adipose tissue in lean and obese young men. Proc Natl Acad Sci USA 2017;114:8649-8654.

23. Hondares E, Gallego-Escuredo JM, Flachs P, et al. Fibroblast growth factor- 21 is expressed in neonatal and pheochromocytoma-induced adult human brown adipose tissue. Metabolism 2014;63:312-317.

24. Zhang HL, Huang YY, Lee HJ, Jin WZ. Zic1 negatively regulates brown adipogenesis in C3H10T1/2 cells. Sci Bull 2015;60:1033-1035.

25. Brill E, Gobble R, Angeles C, et al. ZIC1 overexpression is oncogenic in liposarcoma. Cancer Res 2010;70:6891-6901.

26. Wang LJ, Jin HC, Wang $X$, et al. ZIC1 is downregulated through promoter hypermethylation in gastric cancer. Biochem Biophys Res Commun 2009;379:959-963. 